\title{
Simple Simulation Model: Successful Water Borne Dispersal in Terrestrial Spiders to Reach Lake Islands
}

\author{
HAYASHI Morito \\ (Miyagi University of Education) \\ I Introduction \\ II Materials and Methods \\ III Results \\ IV Discussion
}

Keywords: artificial island, island biology, spider, water-borne dispersal, wind-borne dispersal

\section{Introduction}

Dispersal of organisms and materials influence ecosystems on islands (Grant 1998; Chadwick et al. 1999; MacArthur and Wilson 2001; Muhs et al. 2007; Emerson and Gillespie 2008; Gillespie et al. 2012). For instance, some organisms that arrive and fill vacant niches on newly created islands can critically affect species composition and genetic structure (Mayr 1954; Simberloff and Wilson 1969). Organisms that invade established island ecosystems are also influential according to reports about invasive species on islands (Henneman and Memmott 2001; Alvarez-Castaneda et al. 2010). Dust carried by wind from Asia and Africa contribute soil formation and insular ecosystem developments (Chadwick et al. 1999; Muhs et al. 2007). Although various factors are involved in these invasion/arrival events, it is difficult to directly research dispersal events that lead to new arrival on islands (Carlquist 1974; Chadwick et al. 1999; Muhs et al. 2007; Cook et al. 2010). Currently recognized important passive dispersal mechanisms to reach islands include waterborne (Ikawa et al. 1998; Gregory 1999; Coulson et al. 2002; Calsbeek and Smith 2003), wind-borne (Chadwick et al. 1999; Bell et al. 2005; Muhs et al. 2007; Yang et al. 2009; Soto et al. 2017), 'hitchhiking' with other animals (Gittenberger et al. 2006), and the migration of humans (Henneman and Memmott 2001; Suarez et al. 2001). Water- and 
wind-borne dispersal are especially hard to track and difficult to research due to the effects of turbulent water and wind currents on dispersal (Muñoz et al. 2004; Gillespie et al. 2012). To simplify and emphasise the effects of factors excluding water current from these issues, spiders inhabiting on an artificial archipelago created in lakes at the Attenborough Nature Reserve, UK were selected as a simple model to investigate the dispersal mechanisms by which water borne organisms/materials can reach new land under different geographical and wind conditions (Hayashi and Goodacre 2014). Predominant water currents do not exist in the lakes as a closed water system, resulting to emphasise other factors affecting dispersal events.

It has long been thought that wind-borne organisms that successfully arrive on islands reach them directly, without landing on the water and drifting to shore (Thornton 1997). The aerial flight of wind-borne organisms is highly leptokurtic, with recorded dispersal distances ranging from just a few metres up to thousands of kilometres (Weyman et al. 2002; Thomas et al. 2003), indicating the potential of some organisms to reach even very remote islands. In fact, wind-borne spiders have been captured by aerial traps set on ships or aircraft (Darwin 1839; Hardy and Milne 1937; Okuma and Kisimoto 1981; Foelix 1996). However, the possibility that these aeronauts will land on water is undoubtedly high since $70.6 \%$ of the planet's surface is covered by water. Therefore, windborne dispersal is referred to as an 'aerial lottery', since it is a gamble as to whether an organism will land on a suitable terrestrial habitat (Suter 1999). The evolution of this risky aerial flight has long been a mystery (Darwin 1839). Aeronaut spiders have further unexpected skills, in that they are able to move on the surface of water by raising their legs to use as sails and take advantage of the wind. Spiders that show wind-borne dispersal potential always perform this sailing on water, but the reverse is not true (Hayashi et al. 2015). Wind-borne dispersal may therefore have evolved following the evolution of sailing behaviour. Spiders that land on water after wind-borne dispersal are able to continue their journey using their sailing skills (Hayashi et al. 2015), which is to say that waterborne dispersal of sailing spiders is highly affected by the wind. This sort of abilities/features dispersing through in the air and on water surface might be seen in other organisms/materials, given that windborne objects are generally light weight and highly affected by wind. Spiders were suitable models among aerially dispersing organisms to apply in the simple simulation assumed both wind- and water-borne dispersals in the present study, as dispersers that were well recognized to perform aerial flight and sailing on water with prevailing wind (e.g., Suter 1999; Weyman et al. 2002; Thomas et al. 2003; Hayashi et al. 2015). 
In the present study, it was assumed whether spiders sail straight across on water under four different kinds of wind - from the north, south, east and west - after they land on the water surface among artificial islands created in the middle of lakes located in Attenborough Nature Reserve. The lakes were gravel pits, and waste clay was removed from the gravel to produce concrete, which was then piled at the bottom of the lakes. Initially, no terrestrial organisms existed on the islands, therefore they provided an ideal model of colonization events on young oceanic islands (Hayashi and Goodacre 2014). Significant advantages to using these island models were that they were closed spaces surrounded by a mainland area, hence predominant water currents do not exist, and homogeneity of environmental factors. Spiders that disperse on water surfaces using wind after landing on the water surface were expected to land on the shores of islands or lakes in a relatively short time, because the three lakes used in my analyses were within a $2 \mathrm{~km}^{2}$. Between 24 and 40 islands exist in each lake, and the possibility of waterborne organisms landing on these islands is considerably higher than that for oceanic islands. In the present study, the frequency of spiders landing on the islands via waterborne dispersal in different lakes and under different wind directions was estimated. Adding to this, the overall frequencies of spiders landing on the islands via water depending on assumed survival rates, was also calculated.

\section{Materials and Methods}

The frequency that spiders land on islands or the mainland (shores of the lakes) were estimated in three lakes, known as Coneries Pond, Tween Pond and Main Pond, and where many spider samples had been obtained during previous research at the site. A traced map of Attenborough Nature Reserve was made based on a satellite image obtained from Google Earth (Google Inc.), covering an area of 2,587 by 2,502 m, and which showed all outlines of the lakes and the islands (Fig. 1). The shoreline lengths of 40, 25 and 24 islands in Coneries Pond, Tween Pond and Main Pond, respectively, were measured using the program ImageJ (Rasband 2018).

$50 \mathrm{~m}$ square meshes, aligned in the north-south and east-west directions, were set within a range of 1,850 by $2,200 \mathrm{~m}$, resulting in 323 intersections over aquatic areas (intersections seen on islands were not included to those). Aeronaut spiders were assumed to land at each intersection on the three lakes and sail across the water, blown by four different wind directions from the north, south, east and west. A total of 1,292 patterns of waterborne journeys were tested, expressed as straight lines, for example waterborne 


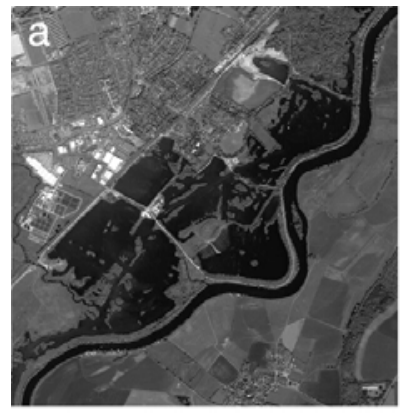

C

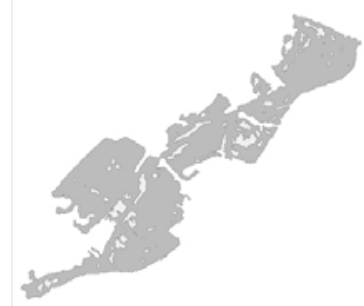

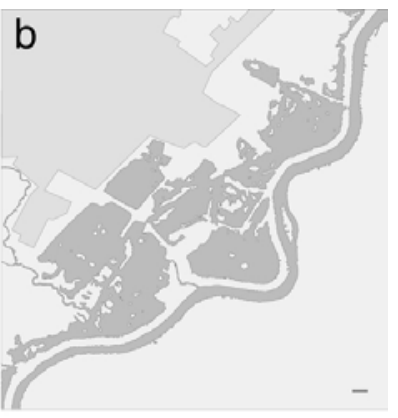

d

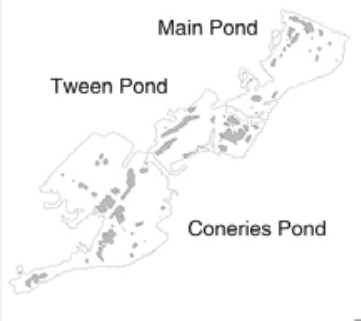

(a) A satellite image of Attenborough Nature Reserve. (b) A traced map based on the satellite image. Maps were used to measure the shoreline lengths of the lakes (c) and artificial islands (d). Scale bars represent $100 \mathrm{~m}$.

Fig. 1. Measurement of shoreline lengths.

dispersals blown by the wind from the true north were drawn as lines directed to true south. It was then determined whether those straight lines indicating waterborne dispersal met the shorelines of islands or lakes.

A likelihood ratio test was performed based on a generalised linear mixed model (GLMM), in which the dependent variable was whether spiders reached islands or the mainland, the explanatory variable was the difference in geography, and wind directions were taken into account as random factors. Multiple comparisons were also performed to estimate the statistical significance between all combinations of explanatory variables. The same model comparisons were carried out but with the explanatory variable changed to wind direction and the random factor changed to lakes. All statistical analyses were run using the $R$ programming language ( $R$ Core Team 2012). Analyses using GLMMs were carried out using the glmer program in the lme4 package (Bates et al. 2013), and multiple comparisons were carried out using glht in the multcomp package (Hothorn et al. 2008).

Each distance of 544 waterborne journeys $(i=1 \sim 544)$ ending to land on islands $D i$ converted by metre were measured using the program ImageJ (Rasband 2018) and the overall frequency of spiders landing on the islands $(N)$ was calculated depending on survival rates on water $(S)$ as $N=\sum_{i=1}^{544} S^{D i / 100}$. The survival rates $S$ were assumed 99.0, 
90.0, 50.0, 10.0 and 1.0\% per $100 \mathrm{~m}$. The overall frequency of spiders landing on the islands via air was calculated as the number of intersections on the islands multiplies four times to be equivalent to the assumption that spiders landed on each intersection on water four times evenly.

\section{Results}

The total shoreline lengths of the lakes and islands, respectively, measured using traced outlines were estimated to be 7,717 and 6,154 $\mathrm{m}$ in Coneries Pond, 4,099 and 3,592 $\mathrm{m}$ in Tween Pond, and 5,112 and 2,660 $\mathrm{m}$ in Main Pond (Fig. 1). Hence, the proportions of total shoreline lengths of islands to lakes were $44.4 \%, 46.7 \%$ and $34.2 \%$ in Coneries, Tween and Main Pond, respectively.

The frequency of spiders arriving at islands or the mainland was recorded based on the $50 \mathrm{~m}$ meshes arranged to cover the three lakes for statistical analyses (Fig. 2). As shown in Fig. 3a, average ratios of arrivals at the islands in the three lakes were
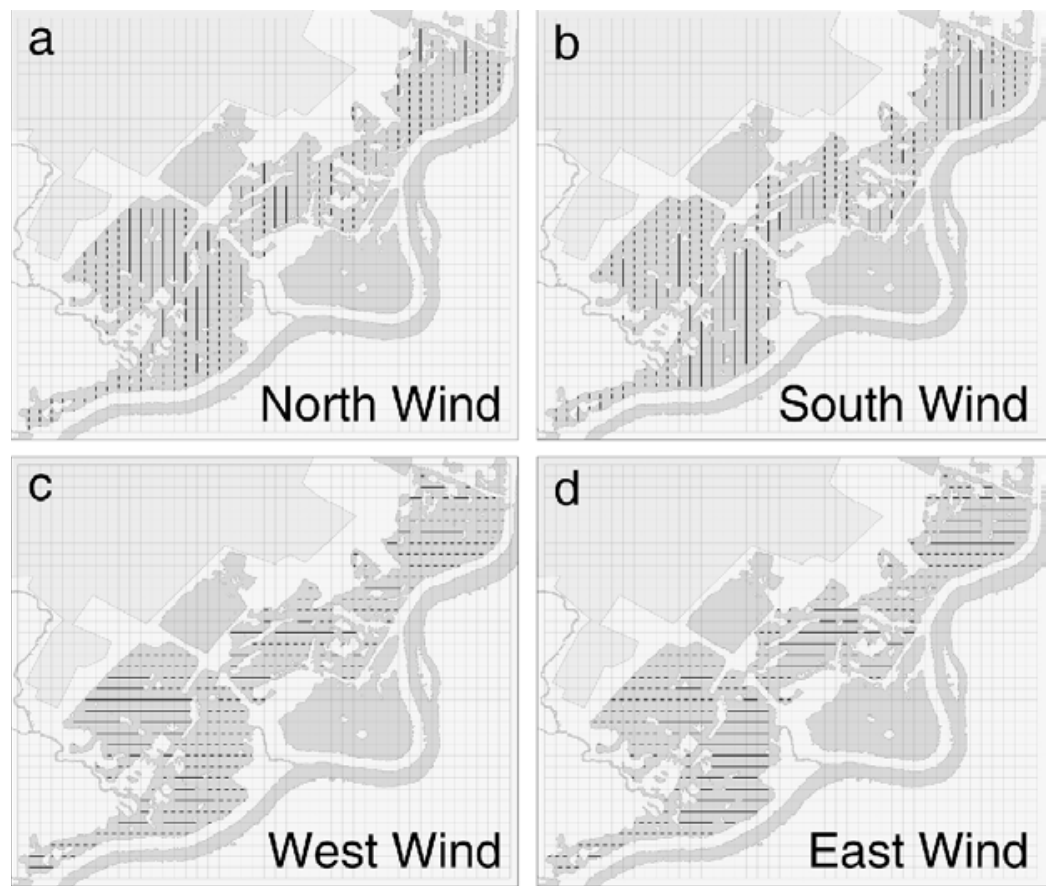

The rate of landing on islands following waterborne dispersal was assumed based on the $50 \mathrm{~m}$ meshes covering the three lakes. Wind-borne spiders were assumed to be blown by (a) North, (b) South, (c) West and (d) East Wind and land on each intersection, and become waterborne dispersers following grid lines until they reached the shore. Bold solid and dotted lines represent water-borne routes that individuals landing on the shore of islands and the mainland respectively.

Fig. 2. $50 \mathrm{~m}$ meshes to estimate landing rates on the islands via waterborne dispersal. 

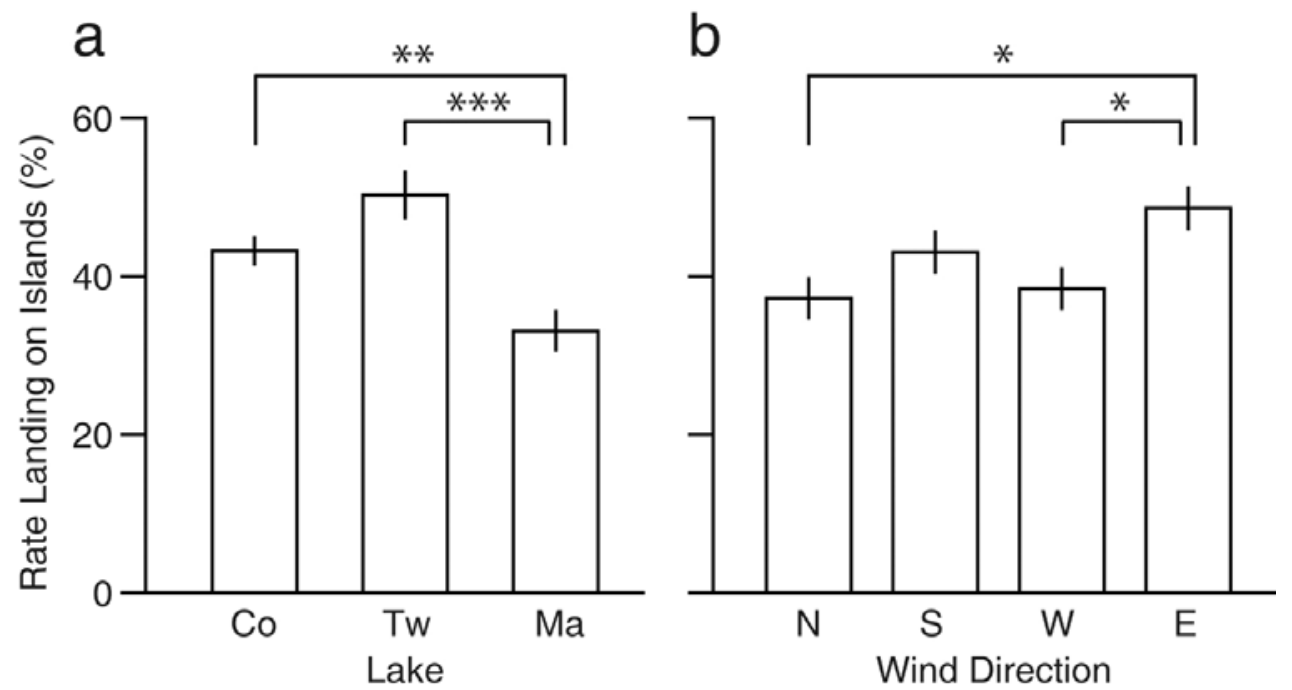

The rates of landing on islands were estimated through a model assuming waterborne dispersal on each lake (a, Co: Coneries Pond, Tw: Tween Pond, Ma: Main Pond) and wind direction (b, N: north, $\mathrm{S}$ : south, W: west, E: east), based on 1,292 measurements. Multiple comparisons based on the GLMM were executed to evaluate the landing rates (*: $\left.p<0.05,{ }^{* *}: \mathrm{p}<0.005,{ }^{* * *}: \mathrm{p}<0.001\right)$. Error bars, s.e.m.

Fig. 3. Estimated rates of landing on islands for different lakes and under different wind directions.

estimated based on the $50 \mathrm{~m}$ meshes covering the lakes, and were $43.3 \pm 1.9 \%$ in Coneries Pond, $50.4 \pm 3.1 \%$ in Tween Pond, and $33.2 \pm 2.6 \%$ in Main Pond. I used a generalized linear mixed model (GLMM) in which random factors took account of possible bias of the results under the four wind directions. When comparing the three lakes, the likelihood ratio test showed that the probability of spiders arriving at islands via waterborne dispersal was likely to be influenced by differences between the lakes $\left(\chi^{2}=19.0, \mathrm{p}=7.62\right.$ $\left.10^{-5}\right)$. A multiple comparison using Tukey's HSD based on the GLMM showed that the probability of arriving at an island was significantly different between Main Pond and the other two lakes (Coneries Pond - Main Pond: $Z=-3.11, p=0.00513$; Tween Pond - Main Pond: $\mathrm{Z}=4.23, \mathrm{p}<0.001)$.

As Fig. 3b shows, the average ratios for arriving at islands under four different wind directions were $37.5 \pm 2.7 \%$ (north wind), $43.3 \pm 2.8 \%$ (south wind), $38.7 \pm 2.7 \%$ (west wind), and $48.9 \pm 2.8 \%$ (east wind). When comparing the four wind directions, the likelihood ratio test based on the GLMM, in which the random factor was the three different lakes, the probability that spiders would arrive at islands via waterborne dispersal was likely to be influenced by wind direction $\left(\chi^{2}=10.9, \mathrm{p}=0.0126\right)$. A multiple comparison using Tukey's HSD based on the GLMM showed that the probability of arriving at an island was significantly different between the north and east winds, and the east and west winds (north - east: $Z=-2.95, p=0.0168$; east - west: $Z=-2.63, p=$ 
0.0426).

The overall frequencies of spiders landing on the islands via water surface $(N)$ under the assumptions of the survival rate 99.0, 90.0, 50.0, 10.0 and $1.0 \%$ per $100 \mathrm{~m}$ of water borne journey were 537, 488, 306, 147, 82 individuals respectively. The average distance of all 544 water-borne routes landing on islands (solid lines shown on water surface in Fig. 2) was $107 \mathrm{~m}$. The number of intersections on the islands were 41 and which was multiplied four times, hence the overall frequency of spiders landing on the islands directly via air was estimated to be 164 individuals (Fig. 4).

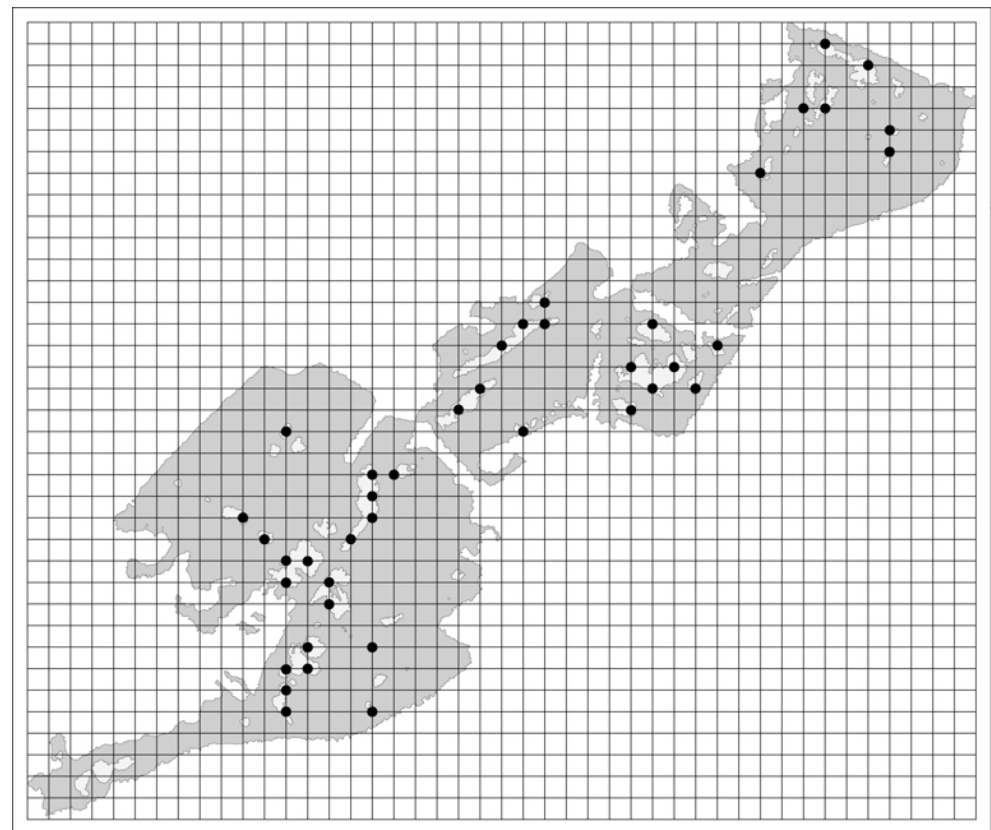

The rate of landing on island following airborne-dispersal was estimated based on the same $50 \mathrm{~m}$ meshes used in Fig. 2. Each intersection on islands was counted.

Fig. 4. $50 \mathrm{~m}$ meshes to estimate landing rates on the islands via windborne dispersal.

\section{Discussion}

The probabilities of arriving at an island via waterborne dispersal, assuming drifting spiders on the water's surface, were significantly different between lakes and wind directions (Fig. 3). Hence, the fate of spiders arriving at islands or the mainland is affected by the situation where the spider lands and the local wind direction. The results described here are thought to reflect both the relative shoreline lengths and the biased distribution of the islands.

The assumption that waterborne dispersers land on the shore where shorelines and 
straight tracks of drifting individuals intersect is acceptable to estimate dispersal rates of aeronautic spiders in a closed water system such as small lakes modelled in the present study, because those spiders that sail on water using their water repellent legs are expected to be influenced by wind rather than water currents. Moreover, prevailing water currents do not exist in the semi-closed lakes studied here. While if even a small part of a disperser's body was submerged under water, then waterborne dispersal may reflect water currents more strongly. Some spiders that show fewer wind-borne tendencies cannot stand on water or perform death mimicry, and keep part of their body submerged when drifting on the surface of water (Hayashi et al. 2015). Therefore, both the physiological abilities and behavioural responses to the water surface may influence the probability of waterborne dispersers reaching islands, and also their likelihood of survival.

The same dynamics potentially work on other organisms/materials drifting on water surface, except for spiders. In the case that a drifting material is water repellent and also highly affected by wind power on water surface, the pattern of its movement is expected to be similar to the sailing behaviour of spiders on water. This type of water borne organisms/materials can be applied in a simple model used in the present study. On the other hand, if the material is hydrophilic and drifting on water surface with the large part of its body submerged under water, the drift must be affected by water current rather than wind. Therefore, the simple model assumed this time is useful only for particular organisms/materials and situations such as small animals that can stand on water (Stratton et al. 2004; Bush and Hu 2006; Hayashi et al. 2015) and closed water systems without current predominantly affecting the movement of drifting objects on water surface. However, the simple model could be a base model to realize precise simulations taking into account of fluid dynamics among wind and water currents including air movement near the water surface.

Although the survival rate of spiders on water is uncertain yet, the survival rates of water striders on water surface may provide with some useful indication. It has been reported that the survival rates of water striders measured $18 \mathrm{~h}$ under higher predation pressure than average in field were around 80 to 85\% (Krupa and Sih 1998). The average distance of all 544 water-borne routes landing on islands was $107 \mathrm{~m}$, which was the distance that spiders can sail across on water within 18 min (simply one-sixtieth of the 18 $\mathrm{h}$ experiment cited above) if the wind speed on the water surface was exceptionally slow as $10 \mathrm{~cm} / \mathrm{s}$. Although the average distance was calculated based on the simplest assumption that spiders moved straight on water surface, survival rate ranged $1.0-50.0$ $\%$ per $100 \mathrm{~m}$ seemed to be extremely small estimations. Even if the survival rate of water 
borne spiders was $50.0 \%$ per $100 \mathrm{~m}, 306$ spider individuals were estimated to land on islands through water borne route, comparing to 164 individuals estimated to arrive directly via air (41 landing intersections multiple four times, hence four different wind directions). Hence, at least the chances for aeronauts to land on islands via the water surface are considerable, except for the traditional assumption of aeronauts landing on islands via direct flights (Thornton 1997).

In conclusion, artificial islands created in the lakes of Attenborough Nature Reserve provide a useful model to estimate waterborne dispersal and conduct research into organisms landing on islands via the aquatic surface without influential currents. The fate of dispersers is affected by the nature of the aquatic area they land on and wind direction. In addition to the biogeography of the mainland (source populations), the distribution of islands and trends in wind direction are also likely to be crucial factors influencing island ecosystems via the arrival of waterborne organisms/materials. Water-borne dispersal following wind-borne dispersal may confer wind-borne organisms/materials more chances to reach islands than it has ever been thought (e.g., Thornton 1997), given that the number of spiders expected to land on the islands via water surface under the assumptions of extremely small survival rates on water was similar to or greater than that of via air. Currently, the simple grid model in the present study is applicable to only particular materials and situations, but the model has a potential to be modified to further accurate models, which simulate the movements of various organisms/materials with taking into account of air and water currents and even interactions between them seen near water surface, when insular ecosystems are raising.

\section{Acknowledgements}

I thank K. Mizota at the Miyagi University of Education for critical review of my manuscript; S. Goodacre and A. Hyde at the University of Nottingham, M. Bakkali at the Universidad de Granada, F. Naggs at the Natural History Museum, London, G. Bowden, T. Sexton, J. Ellis, C. Martin, S. Aitkin, J. Black, A. Hindmarsh and the late K. Corbett from the Attenborough Nature Reserve for helping with the research; an anonymous reviewer who provided constructive criticism; and the Nottinghamshire Wildlife Trust and CEMEX for permission to carry out this research. This work was supported by research grants from the Japan Society for the Promotion of Science (24770013, 15K14597, 16H03051) and the Daiwa Foundation, Japan. 


\section{References}

Alvarez-Castaneda, S. T., Arnaud, G., Cortes-Calva, P. and Mendez, L. 2010. Invasive migration of a mainland rodent to Santa Catalina Island and its effect on the endemic species Peromyscus slevini. Biological Invasions 12 (3) : 437-439.

Bates, D., Maechler, M., Bolker, B. and Walker, S. 2013. lme4: Linear mixed-effects models using Eigen and S4. $R$ package version 1.0-4.

Bell, J. R., Bohan, D. A., Shaw, E. M. and Weyman, G. S. 2005. Ballooning dispersal using silk: World fauna, phylogenies, genetics and models. Bulletin of Entomological Research 95 (2) : 69-114.

Bush, J. W. M. and Hu, D. L. 2006. Walking on water: Biolocomotion at the interface. Annual Review of Fluid Mechanics 38: 339-369.

Calsbeek, R. and Smith, T. B. 2003. Ocean currents mediate evolution in island lizards. Nature 426 (6966) : 552-555.

Carlquist, S. 1974. Island biology. New York and London: Columbia University Press.

Chadwick, O. A., Derry, L. A., Vitousek, P. M., Huebert, B. J. and Hedin, L. O. 1999. Changing sources of nutrients during four million years of ecosystem development. Nature 397 (6719) : 491-497.

Cook, B. D., Pringle, C. M. and Hughes, J. M. 2010. Immigration history of amphidromous species on a Greater Antillean island. Journal of Biogeography 37 (2) : 270-277.

Coulson, S. J., Hodkinson, I. D., Webb, N. R. and Harrison, J. A. 2002. Survival of terrestrial soil-dwelling arthropods on and in seawater: Implications for transoceanic dispersal. Functional Ecology 16 (3) : 353-356.

Darwin, C. 1939. Narrative of the surveying voyages of His Majesty's Ships Adventure and Beagle between the years 1826 and 1836 (1st Ed.), Journal and Remarks Vol. III. London: Henry Colburn.

Emerson, B. C. and Gillespie, R. G. 2008. Phylogenetic analysis of community assembly and structure over space and time. Trends in Ecology and Evolution 23 (11) : 619630.

Foelix, R. F. 1996. Biology of spiders (2nd Ed.). New York: Oxford University Press.

Gillespie, R. G., Baldwin, B. G., Waters, J. M., Fraser, C. I., Nikula, R. and Roderick, G. K. 2012. Long-distance dispersal: A framework for hypothesis testing. Trends in Ecology and Evolution 27 (1) : 47-56.

Gittenberger, E., Groenenberg, D. S. J., Kokshoorn, B. and Preece, R. C. 2006. Molecular trails from hitch-hiking snails. Nature 439 (7075) : 409. 
Grant, P. R. 1998. Evolution on islands. Oxford: Oxford University Press.

Gregory, M. R. 1999. Plastics and South Pacific Island shores: Environmental implications. Ocean and Coastal Management 42 (6-7): 603-615.

Hardy, A. C. and Milne, P. S. 1937. Insect drift over the North Sea. Nature 139 (3516): 510-511.

Hayashi, M. and Goodacre, S. 2014. Artificial islands created through industrial activity contribute to environmental education and evolutionary ecology. Research Bulletin of Environmental Education Center, Miyagi University of Education 16: 39-43.

Hayashi, M., Bakkali, M., Hyde, A. and Goodacre, S. L. 2015. Sail or sink: Novel behavioural adaptations on water in aerially dispersing species. BMC Evolutionary Biology 15 (1) : 118.

Henneman, M. L. and Memmott, J. 2001. Infiltration of a Hawaiian community by introduced biological control agents. Science 293 (5533) : 1314-1316.

Hothorn, T., Bretz, F. and Westfall, P. 2008. Simultaneous inference in general parametric models. Biometrical Journal 50 (3) : 346-363.

Ikawa, T., Okubo, A., Okabe, H. and Cheng, L. 1998. Oceanic diffusion and the pelagic insects Halobates spp. (Gerridae: Hemiptera). Marine Biology 131 (1) : 195-201.

Krupa, J. J. and Sih, A. 1998. Fishing spiders, green sunfish, and a stream-dwelling water strider: Male-female conflict and prey responses to single versus multiple predator environments. Oecologia 117 (1-2) : 258-265.

MacArthur, R. H. and Wilson, E. O. 2001. The theory of island biogeography (Vol. 1). Princeton: Princeton University Press.

Mayr, E. 1954. Change of genetic environment and evolution. In Evolution as a process, ed. J. Huxley, A. C. Hardy and E. B. Ford, 157-180. London: Allen and Unwin.

Muhs, D. R., Budahn, J. R., Prospero, J. M. and Carey, S. N. 2007. Geochemical evidence for African dust inputs to soils of western Atlantic islands: Barbados, the Bahamas, and Florida. Journal of Geophysical Research: Earth Surface 112 (F2): F02009.

Muñoz, J., Felicísimo, Á. M., Cabezas, F., Burgaz, A. R. and Martínez, I. 2004. Wind as a long-distance dispersal vehicle in the Southern Hemisphere. Science 304 (5674) : 1144-1147.

Okuma, C. and Kisimoto, R. 1981. Air borne spiders collected over the East China Sea. Japanese Journal of Applied Entomology and Zoology 25 (4) : 296-298. (in Japanese with an English summary)

R Core Team. 2012. R: A language and environment for statistical computing. Vienna, Austria: R Foundation for Statistical Computing. http://www.R-project.org: ISBN 
3-900051-07-0.

Rasband, W. S. 1997-2018. ImageJ, U. S. National Institutes of Health, Bethesda, Maryland, USA. https://imagej.nih.gov/ij/

Simberloff, D. S. and Wilson, E. O. 1969. Experimental zoogeography of islands: The colonization of empty islands. Ecology 50 (2) : 278-296.

Soto, E. M., Labarque, F. M., Ceccarelli, F. S., Arnedo, M. A., Pizarro-Araya, J. and Ramírez, M. J. 2017. The life and adventures of an eight-legged castaway: Colonization and diversification of Philisca ghost spiders on Robinson Crusoe Island (Araneae, Anyphaenidae). Molecular Phylogenetics and Evolution 107: 132-141.

Stratton, G. E., Suter, R. B. and Miller, P. R. 2004. Evolution of water surface locomotion by spiders: A comparative approach. Biological Journal of the Linnean Society 81 (1) : 63-78.

Suarez, A. V., Holway, D. A. and Case, T. J. 2001. Patterns of spread in biological invasions dominated by long-distance jump dispersal: Insights from Argentine ants. Proceedings of the National Academy of Sciences 98 (3) : 1095-1100.

Suter, R. B. 1999. An aerial lottery: The physics of ballooning in a chaotic atmosphere. Journal of Arachnology 27 (1) : 281-293.

Thomas, C. F. G., Brain, P. and Jepson, P. C. 2003. Aerial activity of linyphiid spiders: Modelling dispersal distances from meteorology and behaviour. Journal of Applied Ecology 40 (5) : 912-927.

Thornton, I. 1997. Krakatau: The destruction and reassembly of an island ecosystem. Cambridge: Harvard University Press.

Weyman, G. S., Sunderland, K. D. and Jepson, P. C. 2002. A review of the evolution and mechanisms of ballooning by spiders inhabiting arable farmland. Ethology Ecology and Evolution 14 (4) : 307-326.

Yang, J., Li, G., Rao, W. and Ji, J. 2009. Isotopic evidences for provenance of East Asian Dust. Atmospheric Environment 43 (29) : 4481-4490. 


\title{
Simple Simulation Model: Successful Water Borne Dispersal in Terrestrial Spiders to Reach Lake Islands
}

\author{
HAYASHI Morito \\ (Miyagi University of Education)
}

\begin{abstract}
keywords : artificial island, island biology, spider, water-borne dispersal, wind-borne dispersal
\end{abstract}

Organisms and materials newly arriving on islands impact insular ecosystems. Therefore, the processes around how they arrive on islands are important to understand, along with the ecological dynamics among islands and the mainland. Dispersal materials are thought to move with wind, water or animals, with some ultimately landing on islands. However, most of these passive movements are difficult to observe and mysteries remain as to how and why those organisms/materials arrive at small terrestrial areas surrounded by a vast aquatic space. This is because islands are often far out to sea, and dispersal patterns can be influenced by various factors. These factors include geographical and wind conditions that influence dispersal routes and their outcome for organisms/materials. In this study, I used artificial islands created in the middle of lakes to estimate dispersal rates of waterborne spiders as the models of organisms/materials, which have the possibilities of both wind- and water-borne dispersal. Dispersal possibilities to these islands are expected to be more likely than for typical oceanic islands. Spiders are known to be one of the first animal groups to invade remote islands at the initial stage when new insular ecosystems are forming. Aeronautic spiders have previously been recorded on the young islands created in the Attenborough Nature Reserve, UK, meaning that those spiders arrived on the islands via air or water. A recent study revealed that spiders that can become airborne can also sail on water using wind power. In the present study, I estimated how spiders landing on the water surface of these lakes dispersed to the islands under different geographical and wind conditions. I showed that the distribution of islands in aquatic space, and wind direction influenced on the rate of spider dispersal to islands. In addition, I also showed that water borne dispersal under even the smallest assumptions of survival rate on water surface effectively contributed airborne spiders to reach islands in the artificial lakes created within a $2 \mathrm{~km}^{2}$. Hence, wind borne 
organisms/materials may arrive at islands via water surface more than they have ever been thought, if they can survive/float on water. A model used in this study is exclusively applicable to estimate the movements of air- and water-borne hydrophobic materials especially in the case that they are highly influenced by wind even on water surface. The simple gridiron model could be a base model to build precise simulation programs taken into account of rheological and current dynamics, to understand dispersal events driven both by wind and water that happens relatively in lightweight materials such as plastic fragments and aeronautic spiders in the future. 